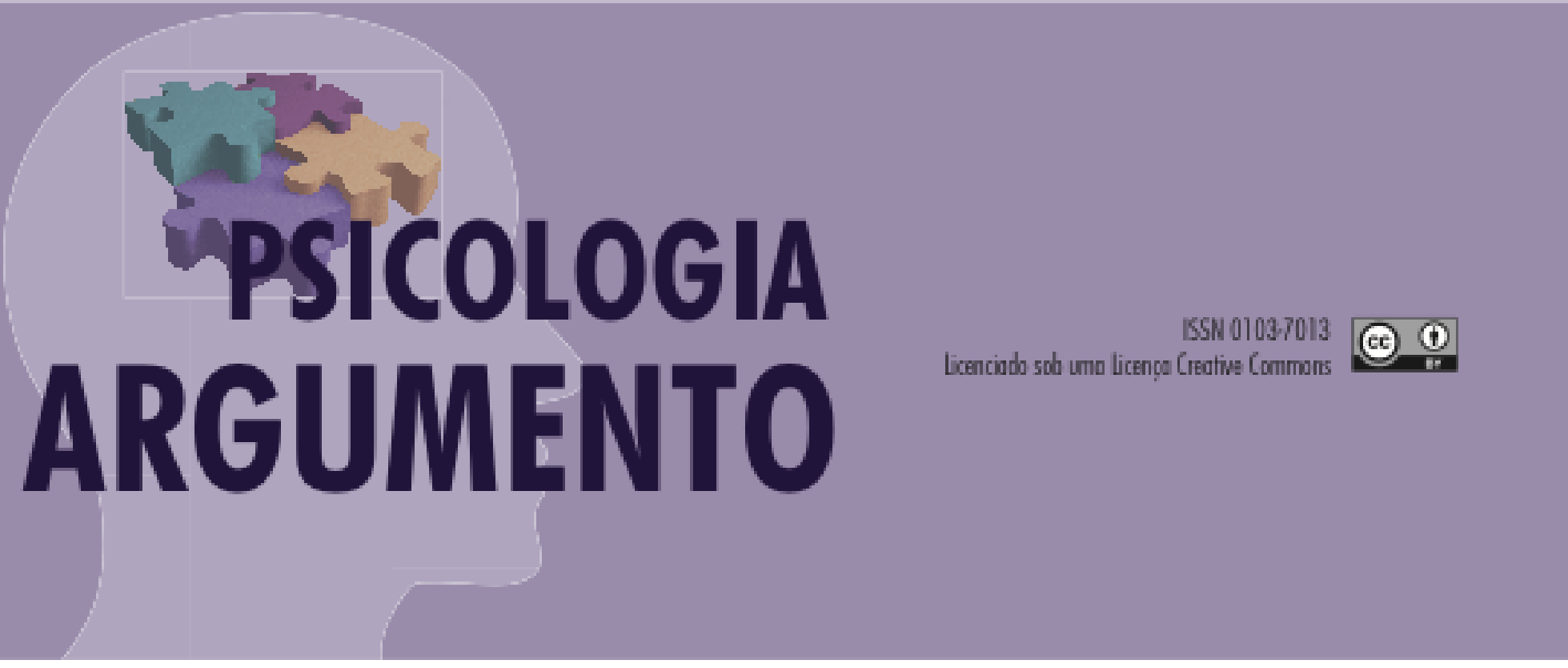

doi $10.7213 /$ psicol.argum.33.082.AO03

\title{
Laudos e pareceres psicológicos e práticas de poder
}

\section{Reports and psychological opinions and practices of power}

\section{Eduardo Ponte Brandão [a]}

[a] Psicólogo do Tribunal de Justiça/RJ, professor do curso de pós-graduação Latu sensu em Psicologia

Jurídica/AVM. Rio de Janeiro - RJ - eduardopbrandao@gmail.com/ edpbr@zipmail.com.br

\section{Resumo}

O trabalho do psicólogo no campo jurídico consolidou-se a partir do advento do Estatuto da Criança e do Adolescente (Lei 8069/90), inserindo-se nas práticas realizadas por equipes interprofissionais. O psicólogo é frequentemente demandado a realizar perícias e confeccionar laudos e pareceres. Através do método da genealogia de Foucault, verifica-se que apesar da herança medicalizante da qual a perícia é portadora, essa se mantém como prática mesmo num campo doutrinário de proteção integral dos direitos da criança e do adolescente. Conclui-se que o direito serve de vetor e, ao mesmo tempo, camuflagem para as estratégias de normalização e disciplina, de modo que a demanda por laudos e pareceres servem a diversas linhas de força, entre as quais, o resgate do poder simbólico do juiz que até então poderia ser afrontada pela corrente medicalizante.

Palavras-chave: Laudo. Perícia. Genealogia. Infância. Juventude. 


\begin{abstract}
The role of the psychologist in the field of law has gained strength since the enactment of the Child and Adolescent Statute (Law 8069/90) which required participation of such professionals in interprofessional teams. Among other things, the psychologist is often required to produce reports and to give his/her expert opinion in a court investigation. In this article we rely on Foucault's genealogical method to support the position that despite its original link to clinical interventions, the psychological expertise has proven its importance in protecting children's and adolescent's rights. We reach the conclusion that the field of law functions both by merging and by disguising strategies of normalization and discipline. In this sense, we can verify how the demand for reports and expert opinions can be linked to several lines of force, among which is the rescue of the symbolic power of the judge, in opposition to advocates of institutionalization which instead concur undermine the symbolic power of the judge.
\end{abstract}

Keywords: Report. Expertise. Genealogy. Childhood. Youth..

\title{
Introdução
}

O trabalho do psicólogo no campo jurídico consolidou-se a partir do advento do Estatuto da Criança e do Adolescente (Lei 8069/90), inserindo-se nas práticas realizadas por equipes interprofissionais previstas em lei, particularmente, através dos artigos $150 \mathrm{e}$ 151. Ao mesmo tempo em que se ampliou exponencialmente o quadro formal de psicólogos nos tribunais de justiça no Brasil, sobretudo, nas Varas de Infância e Juventude e de Família, a produção teórica na área passou, de modo geral, a dar destaque a formas de inserção que ultrapassam o modelo pericial e avaliativo e correspondam a práticas restaurativas, de auto composição de conflitos e tantas outras que sejam minimamente orientadas pelo campo dos direitos humanos da criança e do adolescente (Lago, V. M. Amato, P. Teixeira, P. A. Rovinski S. L. R. \& Bandeira, D. R., 2009).

A despeito da produção teórica abundante e de experiências diversas ligas à psicologia jurídica, o psicólogo ainda é frequentemente demandado a realizar perícias e confeccionar laudos e pareceres (Brandão \& Gonçalves, 2011; Reis, 2009; Brito, 2008; Groeninga \& Pereira, 2003). Em face da forte persuasão que estes exercem sobre os operadores de direito, convém lançarmos luz sobre as práticas de poder que as perícias psicológicas colocam em marcha.

Ao lançarmos mão de um retrospecto histórico, de acordo com a genealogia de Foucault, pretendemos verificar a hipótese de que, apesar da herança medicalizante da qual a perícia é portadora, ela se mantém como prática mesmo num campo doutrinário de proteção integral dos direitos da criança e do adolescente.

\section{Perícia judicial e produção de verdade}

Historicamente a associação das práticas judiciárias com o campo das perícias gira em torno da extração de verdade. Sem dúvida central, não se trata da produção de verdade associada às práticas de inquérito que marcaram o nascimento da democracia ateniense $\mathrm{e}$ do pensamento platônico, tal como Foucault descreve em suas conferências de "A Verdade e as Formas Jurídicas" (1996). A entrada da perícia na cena jurídica se deu em época mais recente, particularmente a partir dos séculos XVIII-XIX e, mais especificamente, no cenário criminológico. 
Para tanto, é importante retratar que tais séculos correspondem ao momento de forte industrialização e, assim, de acumulação de novas formas de riqueza industrial e agrícola, fazendo surgir a necessidade de protegê-las da depredação e das revoltas populares e proletárias. Com efeito, como Foucault (1996) descreve, destacou-se uma nova forma de controle e penalidade de tal maneira que caracterizará a sociedade contemporânea: a disciplina: "A sociedade contemporânea (...) merece o nome de "sociedade disciplinar"” (Foucault, 1996, p. 79).

A disciplina responde à necessidade de utilização racional, intensa e máxima do corpo, constituindo-se como uma das precondições da implementação do capitalismo. Ela implica uma técnica que se inscreve materialmente no corpo humano, manipulando os elementos de suas ações, produzindo comportamentos, em suma, fabricando o tipo de homem que se fez necessário para o funcionamento e a manutenção dessa forma de organização social (Rabinow, 1999).

Ao controlar os indivíduos em suas ações e aperfeiçoar ao ápice suas capacidades, a disciplina tratou nas sociedades industriais de não simplesmente impor limites e sim aumentar a utilidade econômica da população e diminuir sua capacidade de revolta. Com efeito, ela se inseriu e floresceu nas mais diversas instituições (a fábrica, o hospital, o exército, a escola), embora encontrando o seu principal ponto de apoio na prisão.

Se até então, nas sociedades ditas de soberania, a prisão não era vista como a punição em si, mas o meio de evitar a fuga daquele que seria punido e supliciado em praça pública, nas sociedades disciplinares ela passou a aglutinar outras funções. Tratou-se de utilizá-la para punir, mas, ao mesmo tempo, por meio da pena, isolar, vigiar, controlar, conhecer e corrigir cada indivíduo que estivesse sob seu domínio. Funcionando como uma espécie de micro tribunal, a prisão adquiriu o papel de excluir o criminoso para incluí-lo e fixá-lo às normas e disciplinas. Consequentemente, ela produz um saber sobre aquele que é mantido sob vigilância, dando origem às técnicas de exame e mantendo-se como a grande punição do século XIX até os dias de hoje.

A tarefa de enquadrar e de individualizar o criminoso foi ao encontro de uma reforma penal inspirada na doutrina positivista. Através desta, passou-se à percepção de que as leis não acarretavam o mesmo efeito de intimidação sobre todas as pessoas. Por conseguinte, para apaziguar os efeitos sociais do crime, de modo que não fosse mais repetido, tornava-se necessário calcular a punição não apenas de acordo com o crime, mas com "as características singulares de cada criminoso" (Foucault, 1987, p. 90). A partir de então, o indivíduo passou a ser considerado através de suas virtualidades, ou seja, do que ele poderia ou estivesse na iminência de fazer e não mais a partir de seus atos.

Nessa nova economia punitiva, o foco passou a ser a natureza do infrator, sendo julgar por si só menos essencial do que "corrigir, reeducar, curar" (Foucault, 1987, p. 15).

Foi assim que, mais do que nunca, a justiça se aparelhou de peritos, por meio dos quais se poderia estrategicamente introduzir a figura do infrator que supostamente preexistiria ao cometimento do crime. Tais peritos encarregavam-se de realizar os exames que compunham o veredicto, lançando luz sobre as circunstâncias atenuantes do crime e tudo o mais "que pretendendo explicar um ato", escreve Foucault, "não passam de maneiras de qualificar um indivíduo" (Foucault, 1987, p. 21-2). Seguindo esse raciocínio, os dados biográficos passam a serem introduzidos com objetivo de justificar o ato criminoso a partir do indivíduo e, portanto, construir a afinidade entre o criminoso e seu crime. 
Nesse campo destacaram-se os métodos positivistas de Lombroso, que eliminaram a religiosidade que cercava a punição dos delitos e crimes e deram origem à criminologia positivista. O exame clínico encabeçado pelo homem da ciência passou a divergir da instrução criminal, fazendo com que os atos em si perdessem relevância frente às categorias mórbidas que justificariam esses mesmos atos. Seguindo esse raciocínio, Lombroso buscava estigmas físicos que apontassem para a presença de traços congênitos de anomalias que estariam na raiz de certos comportamentos delituosos.

Ao mesmo tempo, nesse contexto, começou-se a erigir a "humanidade" do criminoso como limite a ser respeitado. O "Homem" constituiu-se como a fronteira a ser preservada em comparação aos antigos excessos vingativos do soberano. "Homem" e "medida" passaram a ser a justificativa moral para a suavização das penas, cujos valores nasceram "nas próprias táticas do poder e na distribuição de seu exercício" (Foucault, 1987, p. 92). Se o poder soberano foi alvo de crítica de reformadores do século XVIII, não foi porque o soberano abusava de sua força e sim porque havia uma gestão irregular, dispendiosa e, em suma, ruim do poder de punir.

Curiosamente, os crimes pareceram também adquirir certa "suavidade", dirigindose menos aos corpos e mais contra a propriedade, causando a impressão de que a brandura atingiu tanto o campo da punição quanto o da criminalidade. De um lado, a justiça suavizou-se na medida em que se tornou mais meticulosa, ramificando-se nos recônditos das pequenas delinquências que até então eram toleradas. De outro lado, as agressões físicas e os assassinatos cederam lugar ao roubo, à pilhagem, à vigarice e à fraude (Foucault, 1987).

Foucault observa que esse quadro geral de abrandamento e de humanização esteve ligado à "modificação no jogo das pressões econômicas, de uma elevação geral do nível de vida, de um forte crescimento demográfico, de uma multiplicação das riquezas e das propriedades e "da necessidade de segurança que é uma consequência disso"' (Foucault, 1987, p. 71). Dito de outra maneira, o surgimento da economia punitiva moderna, mais branda e mais meticulosa, exigiu o desenvolvimento de técnicas mais sofisticadas de controle, a valorização jurídico-moral das relações de propriedade e uma vigilância mais atenta da multiplicidade e das forças que uma população representava.

Donde a produção de um "dispositivo da sexualidade", para o qual as perícias judiciais no campo criminológico foram de fundamental importância (Foucault, 1994).

Foi a partir delas que surgiram os primeiros tratados de psicopatologia sexual que consideravam o instinto como anormal e sem objetivos procriadores, ressaltando que, antes deles, o estudo científico dos comportamentos vistos como perversos já ocupava o centro das perícias judiciárias ao longo de todo século XIX. A partir de então, o instinto sexual passou a ser localizado na raiz das doenças mentais e do comportamento em geral, assumindo, assim, relevância central na patologia psiquiátrica e se transformando em objeto de interesse da medicina. Acreditou-se que as manifestações patológicas no adulto, dito anormal, seriam tributárias da ausência de controle adquirido no desenvolvimento infantil em relação aos instintos sexuais, de natureza propriamente perversa.

Tais tratados de psicopatologia sexual abrandaram as legislações penais que outrora, sob forma de inquérito, incidiam sobre os atos reconhecidos como perversos. $\mathrm{O}$ exame clínico encabeçado pelo homem da ciência não se limitava à descrição detalhada do comportamento delituoso, divergindo, portanto, da instrução criminal. Os atos em si perderam importância na busca de elementos que delimitavam as categorias mórbidas que 
justificariam esses mesmos atos, permitindo que as perversões fossem a partir de então despenalizadas. Logo, a inclusão da perversão na sexologia médica despojou a competência dos juízes (Foucault, 2011).

É verdade que essa normalização científica do sexual não teria ocorrido se, além das perícias criminológicas, a medicina não tivesse se inscrito no campo das famílias. Ora, foi através da atribuição de falhas constitutivas da infância na etiologia do anormal que a psiquiatria se ramificou num conjunto amplo de instituições do século XIX-XX, principalmente, através dos aparelhos de controle jurídico-pedagógico.

Não por menos o "mercado da infância" foi o principal ponto de apoio para a abertura do que Donzelot chama de uma perícia psiquiátrica restrita para uma perícia generalizada (Donzelot, 1980). Com essa transposição, abriram-se as portas para que a psiquiatria concentrasse a fonte dos distúrbios na família e discriminasse as causas das anomalias entre a ausência de disciplina, de um lado e de outro lado, a presença de degenerações.

Desde o fim do século XVIII, passou-se a acreditar que os perfis dos "monstros" do judiciário já poderiam ser identificados desde as suas infâncias, de forma atenuada, no interior das famílias. Dizia-se: os pequenos masturbadores de hoje podem se tornar os loucos criminosos de amanhã. Tal raciocínio tinha como efeito a conexão entre as irregulares intra e extrafamiliares. Logo, as perícias psiquiátricas no campo criminológico foi um dos alicerces principais que, associado à busca de degenerações na sexualidade infantil, ampliou o arco de ação da psiquiatria a ponto de se imbuir da tarefa de proteção da ordem social e da raça humana, pretendendo, assim, gerenciar e legislar sobre as uniões conjugais e familiares (Foucault, 2011).

A psiquiatria deixou de ser uma mera gestora da loucura para se transformar na gestora privilegiada da ordem social, sendo necessário que, para tanto, ela incorporasse em seu campo de conhecimento a ideia de que uma doença, vício ou defeito poderia causar, de uma geração a outra, qualquer outra anomalia: alcoolismo, tuberculose, doença mental, comportamento delinquente, etc. Bastaria encontrar em qualquer ponto da hereditariedade um desvio para explicar a emergência de um "estado mórbido" no indivíduo descendente. Em suma, a teoria psiquiátrica da hereditariedade e da degenerescência atribuía aos ascendentes a responsabilidade das aberrações que se constatavam nos descendentes (Foucault, 2011).

A anamnese dirigida pelo médico exerce uma importância fundamental na busca de dados sobre a degenerescência do indivíduo, pois "se a marca de sua realidade não se inscrevia no corpo, deveria aparecer sob a forma de predisposições que se revelariam através de lembranças infantis (...), indicando os antecedentes da doença" (Garcia-Roza, 2000, p. 29) como pertences à família. Portanto, uma descoberta da medicina do século XIX foi a técnica do interrogatório que visava a obtenção de uma confissão, isto é, o reconhecimento, por parte do paciente, de sua própria loucura.

Encontramos novamente, embora no plano das alianças conjugais e familiares, o sujeito visto em sua virtualidade, cabendo à psiquiatria antecipar e administrar as diversas formas de manifestação de anomalias que podem afetar a ordem social. Nesse contexto, a psiquiatria se transforma em estratégia biopolítica que percorre o espaço social e intervém nos pequenos desvios de conduta, abrangendo a quase totalidade dos assuntos humanos.

A partir de então, a psiquiatria não se satisfez mais em dar pequenas orientações à higiene privada e sim assumir de vez a indicação e a contraindicação das uniões conjugais 
e familiares. A degeneração foi o ponto de apoio essencial para a medicalização da vida humana em seus pormenores, pois incidia sobre a reprodução, ou seja, aquilo do qual escapavam os prazeres, mas que ao mesmo tempo transmitia a anomalia entre as gerações, de uma aliança conjugal à aliança familiar e vice-versa. Para os médicos, tratou-se de edificar a sexualidade em negócio de Estado, passando por cima do arbítrio familiar e da moral cristã. (Donzelot, 1980).

Por sua vez, o projeto de profilaxia das anomalias não deixou de enfrentar certos obstáculos, esbarrando, inclusive, numa tendência familiarista - também nacionalista e, cabe destacar, jurídica - que preconizava o abrandamento do controle sobre a família pelos aparelhos do Estado. A luta entre ambas as correntes foi fundamental, vale dizer, para o sobrepujamento da psicanálise em relação à psiquiatria enquanto tecnologia estratégica do biopoder, fato ocorrido em boa parte do Ocidente moderno. Donde a multiplicação, em meados do século $\mathrm{XX}$, de psicanalistas, assim como de psicólogos, conselheiros e especialistas da vida familiar e da liberação sexual que se tornaram "nossos novos diretores de consciência" (Donzelot, 1980, p. 170).

Donzelot (1980) descreve o contexto da França no qual a psicanálise destituiu a família de parte de seus antigos poderes, sem, contudo, anulá-la, atribuindo-lhe novas tarefas educacionais. Logo, na batalha entre a tendência familiarista e a tendência medicalizante, triunfou a primeira ao se apoiar na psicanálise e reverter estrategicamente para si o tema da educação e da liberação sexual enquanto instrumento privilegiado de profilaxia.

Para tanto, foi crucial a formação entre os anos 30 e 40, de um núcleo familiarista chamado Escola de Pais, cuja preocupação inicial era o problema da desadaptação infantil na escola. Foi através desse vínculo entre família-escola que se alavancou a difusão social da psicanálise, substituindo uma psiquiatria da degenerescência que, com seus diagnósticos fatalistas, não parecia mais cumprir seu papel regulador. Nesse movimento, ela modificou as funções da família, sem deixar de salvaguardar a sua importância na formação individual e na qualificação social de sua descendência. No caso francês, a psicanálise jogou com a estratégia educacional da família, transformando-a mais uma vez em objeto e agente de normas relacionais, só que agora, de cunho psicológico e não médico-pedagógico (Donzelot, 1980).

Assim, desde a segunda guerra mundial, as linhas de transformação da família desqualificaram o antigo círculo médico e religioso em proveito de um novo enquadre: o psi. Cabe observar que não se tratou de reforçar pura e simplesmente a família, quando, na verdade, ela foi, em parte, dissuadida. A expansão, em especial, da psicanálise permitiu não somente o afrouxamento das nosografias psiquiátricas, mas também a flexibilização das relações de aliança. Com efeito, de pilar da sociedade, a família passou a ser, nos discursos psi que floresceram nessa época, o lugar que corre permanentemente o risco de se desfazer. Donde se conclui que a chamada "crise da família" e a solução psi são um só mesmo processo político (Donzelot, 1980).

Nesse panorama, a psicanálise e os demais discursos psi extrapolaram o domínio da escola e conquistaram inúmeras instituições, entre as quais, as do aparelho judiciário. Apesar de também penetrar nas Varas de Família, foi na "Justiça de Menores" que, no contexto francês, a psicanálise teve forte influência, a ponto de fazer com que o jurídico retomasse suas formas de intervenção moral e controle sobre as famílias. Ao associar-se à psicanálise, tornou-se possível resgatar as atividades normalizadoras na medida em que se 
conseguia dissolver a resistência das famílias e chamar os pais a assumirem a responsabilidade perante os filhos. Mais ainda, foi por meio da própria psicanálise que a figura do psiquiatra abandonou o cabedal de cientista positivista e se transformou num aliado das práticas pedagógico-preventivas do juiz, desfazendo o hiato que existia antes entre os dois. Em suma, a psicanálise abriu as portas para a ascensão do perito-psiquiatra na cena jurídica e, ao mesmo tempo, permitiu a ampliação do poder simbólico do juiz, mesmo em lhe fazendo escapar ainda mais os mecanismos decisórios (Donzelot, 1980).

Em resumo, vimos até esse momento que a perícia saiu da restrita esfera criminológica, na qual o médico era a figura de proa, para o campo mais geral da infância e juventude e da família, ampliando-se de tal maneira que assumiu uma importante função estratégica de tutela e de normalização social, preservando o poder simbólico do juiz, porém, aglutinando outros saberes, desde que centrados na infância. Feita essa breve genealogia, convém agora examinarmos o caso brasileiro, buscando algumas aproximações com o contexto histórico-político que marcou o contexto francês e o Ocidente em geral.

\section{A psicologia no judiciário brasileiro}

De forma semelhante ao que ocorrera em outros países, a entrada da medicina, já profundamente marcada, como vimos, pelo higienismo e pela teoria da degenerescência e hereditariedade, abriu território para a formação lenta e gradual das equipes interdisciplinares no judiciário, no Rio de Janeiro e noutros estados, concentradas inicialmente no Juizado de Menores. Vale frisar, tal fenômeno deve ser compreendido a partir das razões que historicamente levaram o Estado a estabelecer normas de regulação das famílias, utilizando-se de estratégias distintas em relação às classes sociais e a cada individualidade. A invasão do serviço social e, mais tardiamente, da psicologia, no poder judiciário correspondeu a uma profunda e gradual intervenção do Estado sobre a população através de uma rede complexa de instituições disciplinares e punitivas (Fávero, E. Melão, M. \& Tolosa, J., 2005).

Em meio a essas engrenagens de dominação, a categoria de "menor" passou a ter importância estratégica nos discursos oficiais dos órgãos de assistência, educação e justiça. Retrospectivamente, se as primeiras menções à expressão "menor" figuravam no Código Criminal do Império, foi no final do século XIX que ela passou a designar crianças e adolescentes oriundos das camadas mais baixas da pirâmide social, assumindo, assim, conotação de controle daqueles considerados suspeitos e potencialmente perigosos, numa clara associação entre perigo e pobreza. Com efeito, o problema do "menor" potencializou-se como objeto de preocupação na passagem do Brasil Império para o Brasil República, cujo alvo visava principalmente à correção e ao reajustamento das famílias pobres de acordo com os padrões dominantes da época, respondendo a uma inquietação oriunda, nesse contexto de época, da abolição da mão de obra escrava e do crescimento dos centros urbanos. Donde o aparecimento de argumentos eugenistas em favor da imigração europeia, cujos teóricos defendiam a importância da "melhoria da raça brasileira" e alertavam sobre os riscos de "degenerescência" em função da quantidade de negros no país (Piedade, 2011).

Esse panorama permitiu que os discursos científicos tivessem como papel a naturalização das diferenças sociais, vistas como expressão de anomalias. A ociosidade, a 
indolência e os vícios passaram a ser associados aos pobres, e a miséria que os afetava seria derivada de sua preguiça e de sua inferioridade. Desse modo, os saberes científicos sobre a infância, entre eles a pediatria, a pedagogia e a puericultura, assim como as influências, já vistas acima, da escola positivista de Lombroso e das noções de degenerescência, predisposição ao crime, tendências antissociais e transmissão hereditária, revelaram-se fundamentais na discriminação que começava a se aprofundar entre a "criança" - oriunda de famílias ricas ou burguesas - e o "menor" - filho de famílias pobres ou proletárias.

A distinção entre os conceitos "criança" e "menor" expressam origens de classe, sendo o conceito de infância nitidamente uma construção burguesa (Donzelot, 1980). Tal como ocorreu em boa parte do Ocidente, no Brasil as famílias provenientes da elite econômica e intelectual foram cooptadas pelos discursos médicos e pedagógicos, ao passo que os segmentos pobres da população foram capturados tanto pelo campo da assistência quanto pelos registros da polícia e da justiça. Dessa forma, a expressão "menor" preencheu a necessidade de diferenciar os bem-nascidos e os potencialmente "perigosos" para a sociedade, introduzindo uma fronteira entre "crianças" e "menores em situação irregular", a estes creditando riscos sociais de ruptura da ordem. Em função dos "riscos" que evidenciavam, os "menores" foram sistematicamente internados, afastados de suas famílias, enquanto que as "crianças" - que, no século XIX, eram enviadas para os grandes internatos - passaram a ser educadas junto aos seus núcleos familiares de origem, após o disciplinamento de seus membros pelo higienismo. A assimilação de discursos psicológicos que começavam a influenciar os meios acadêmicos europeus e norteamericanos na virada de século foi essencial para o estabelecimento de parâmetros de "normalidade" e "anormalidade", associando as condutas boas e saudáveis aos modelos familiares dos mais ricos, ao passo que padrões de conduta das camadas mais pobres passaram a ser vistos como desviantes, patológicos ou irregulares, termos comumente empregados para condenar a liberalidade sexual e afetiva entre ex-escravos ou pessoas oriundas de grupos de estrato social mais baixo (Piedade, 2011).

Nessa démarche, a entrada na cena política da classe trabalhadora, em especial, do operariado urbano no Brasil, nos anos de 1930 foi fator decisivo para o agravamento da questão social e, consequentemente, das ações de controle do Estado. Ou seja, a ação estatal se aprofundou com a precarização das condições de vida das famílias proletárias e dos segmentos sociais não incorporados ao processo de urbanização pela via do assalariamento. No campo assistencial, as ações caritativas da Igreja Católica se mostravam insuficientes do ponto de vista da tecnologia que o processo capitalista de organização social exigia. Assim, a assistência passou a ser, assim, cada vez mais arranjada pela ótica do Estado, tornando-se mais técnica e racional, ainda que as bases de recrutamento profissional continuassem a ser organizadas pela Igreja Católica (CFESS, 2003).

A ação profissional de caráter técnico-científica, burocrática e ideológica não se limitou ao campo da assistência, mas passou a compor igualmente outros campos de intervenção social: a saúde, educação e justiça. Nesse último caso, a legislação passou a ser um importante dispositivo regulador e justificador da intervenção do Estado nas relações sociais, materializando o sentido classista do Estado capitalista. As funções públicas se ampliaram e passaram a incorporar o que até então pertencia ao domínio privado. O Estado expandiu o aparato legal-assistencial e normativo com objetivo de 
enfrentar, de acordo com uma racionalidade científica, técnica e ideológica, as expressões de questão social, dominando, em especial, as funções educativas exercidas pela família. A família passou a ser vista como célula mater necessária à reprodução material e espiritual das novas relações de produção e de sociabilidade (CFESS, 2003).

Temos então em 1927 o primeiro Código de menores (Lei n ${ }^{\circ}$ 17.943, de 12 de outubro) no Estado brasileiro que, vale dizer, antecedeu em poucos anos o Estado Novo de Vargas, ao passo que o segundo virá mais tarde, como veremos adiante, em 1979, sendo ambos ligados a ditaduras políticas. Portanto, ambos os códigos tomavam como prerrogativa legal, como vimos, a Doutrina da Situação Irregular e, portanto, partilhavam o entendimento de que apenas os "menores em situação irregular" seriam objeto do direito. Tal concepção doutrinária permitiu que o Estado avocasse o direito de suspender o pátrio poder que por abuso de autoridade, negligência, incapacidade ou impossibilidade, faltasse habitualmente ao cumprimento de seus deveres.

Embora se fizesse presente socialmente sob o modo de práticas e discursos, a psicologia não era regulamentada enquanto profissão, vindo a ocorrer somente em 1962. Em sendo assim, não havia obviamente a presença dele no texto legal. Por sua vez, com o predomínio do discurso higienista, a figura do psiquiatra não deixa de ser ostensiva.

Conforme dispunha o artigo 148, a figura do "medico-psiquiatra" compunha o pessoal do Juízo de menores, do qual não havia, no texto da lei, nenhuma menção ao assistente social, tampouco ao psicólogo. No artigo 150, competia ao profissional da medicina psiquiátrica "proceder a todos os exames médicos e observações dos menores levados a juízo, e aos que o juiz determinar", "fazer às pessoas das famílias dos menores, visitas médicas necessárias para as intervenções dos antecedentes hereditários e pessoais destes" e, por fim, "desempenhar o serviço médico do Abrigo anexo ao juízo de menores". Enfim, o artigo 175 estabelecia que o menor seria submetido pelo juiz, após o recebimento do inquérito policial, "a exame médico-psicológico e pedagógico" com objetivo de "informar o seu estado físico, mental e moral", assim como "da situação moral, social e econômica dos pais, tutor encarregado da sua guarda".

A restrição da lei a menores em situação irregular fazia com que crianças e adolescentes pobres fossem apreendidos, diagnosticados e submetidos a tratamentos baseados na lógica da internação, sem nenhum apoio à família. Segundo o texto legal, os "atos contrários à moral e aos bons costumes" ou de "deixar o filho em estado habitual de vadiagem, mendicidade, libertinagem, criminalidade" e "tiver concorrido para a perversão deste" era motivo suficiente para a destituição do pátrio poder, com a ressalva de que o juiz ou tribunal poderia deixar de aplicar a suspensão do pátrio poder, "se o pai ou mãe se comprometer a internar o filho ou os filhos em estabelecimento de educação, ou garantir, sob fiança, que os filhos serão bem tratados". Assim, observamos que a doutrina da situação irregular fazia com que o menor fosse visto em estado de patologia social, portador de necessidades, sem haver qualquer menção a seus direitos e sim a "medidas terapêuticas e corretivas", ao mesmo tempo que penalizava a família a ponto de destituí-la do pátrio poder.

Havia uma clara associação entre o "fato qualificado como crime ou contravenção ", "o estado físico, mental e moral do menor e a situação social, moral e econômica dos pais", sugerindo de forma sub-reptícia a identificação entre pobreza, doença e criminalidade. A forte tutela que pesava sobre os ditos menores e suas famílias inspirava- 
se com ênfase na ideia de perversão cuja leitura, por sua vez, ficava a meio caminho entre uma versão penal e outra medicalizante.

Nesse código, o poder do psiquiatra encontrava-se subjugado à autoridade do Juiz, de tal modo que era muito comum à época que este último fosse visto como "Juiz-pai" (Zamora \& Pereira, 2013) ou "Juiz-bondoso" (Amaral \& Silva, 1999). A sombra do paternalismo e os arbítrios do Estado cercava a figura do Juiz. Apesar disso, não há dúvidas quanto à presença da tendência medicalizante, com forte influência da criminologia positivista e do eugenismo cientifico.

Sob a doutrina do código de menores, foi fundado em 1936 o Laboratório de Biologia Infantil cujo objetivo era auxiliar o Juízo de Menores na formulação de critérios para a institucionalização de menores, bem como oferecer subsídios para os programas desenvolvidos nos estabelecimentos correcionais. Dito de outro modo, o Laboratório visava a estabelecer bases científicas para a destinação asilar dos menores qualificados em situação irregular. Numa época em que a sociedade conferia grande crédito à ciência, o Laboratório seria encarregado de desvelar os fatores psíquicos, sociais, intelectuais e orgânicos que estariam supostamente na gênese do comportamento delinquente. É digno de nota que a equipe do Laboratório de Biologia Infantil fosse composta por representantes da intelectualidade brasileira, encarregados de apresentar à sociedade as teorias mais avançadas da época, incorporadas do pensamento europeu com evidente propósito de controle social (Piedade, 2011).

Foi nesse contexto jurídico, punitivo e tutelar que surgiram as primeiras referências ao discurso psi, na corrente de preocupações com o destino que deveria ser dado à "infância desadaptada" e às "crianças difíceis". A partir de então, os instrumentos de avaliação e diagnóstico psicológicos foram sendo paulatinamente incorporados pelas instituições de abrigo e/ou correção de menores, a despeito de, como já dito, a própria profissão de psicólogo não ser ainda reconhecida à época. Assim, o "menor" transformouse num dos primeiros objetos de estudo na história da psicologia brasileira, cujo campo de saber viria a se inserir na esteira dos instrumentos de adaptação e controle social. Por fim, com a anexação do Laboratório de Biologia Infantil ao Instituto Sete de Setembro em 1938, tornou-se ainda mais claro seu modelo de ação: investigar e classificar social, médica, pedagógica e psiquicamente o "menor" como meio de promover o resgate do "desviante", enquadrando-o à normatividade dos registros de mão-de-obra infanto-juvenil (Piedade, 2011).

Com a instauração do Estado Novo, no ano de 1937, percebe-se a crescente ideologização dos discursos dos representantes do Estado no atendimento à infância e à juventude. Na ditadura implantada por Getúlio Vargas, intervir junto à infância tornou-se uma questão de defesa nacional. A almejada assistência centralizada é implantada em 1941 por seu governo, com a criação do Serviço de Assistência a Menores (SAM), tornando-se um órgão com alcance nacional somente em 1944.

Rizinni \& Rizinni (2004) destaca um estudo realizado por uma "psicologista do SAM" junto a 3.000 menores como demonstração clara da produção de significados sobre uma população que se pretendia manter submissa ao poder técnico-científico do Estado. Na ocasião, foi aplicado um teste de Q.I. cujo resultado foi de que $81 \%$ do público-alvo era formado por "sub-normais". Seguindo o raciocínio da época, as "condições sômato-psíquica, material e moral de 3.000 menores" levaram o diretor do SAM a concluir que é 
necessário empreender "novos esforços em questão de eugenia e assistência integral do Estado" (Rizinni, I. \& Rizinni, I., 2004, p. 31).

Em seguida, o processo de expansão nacional do SAM fez com que o órgão fosse tomado por relações clientelistas e uso privativo de suas funções públicas. No imaginário popular, o SAM acabou por ser transformar numa instituição de prisão de "menores transviados" e de uma "escola de crime". A imprensa teve papel relevante na construção desta imagem, contribuindo para que, em meados da década de 1950, autoridades públicas condenassem o órgão e propusessem a criação de um novo instituto.

Em 1959, a ONU sancionou a Declaração de Direitos da Criança, embora os efeitos desse texto no Brasil não tenham sido imediatos. Em 1964, surge a FUNABEM, instalada no primeiro ano do golpe militar de 31 de março, cuja ditadura militar perduraria por vinte anos. As propostas que surgem para a instauração desse novo órgão nacional centraram-se na autonomia financeira e administrativa da instituição e na rejeição à imagem de "depósito de menores". A "segurança nacional" tornou-se o seu sustentáculo ideológico, resgatando o ideário de defesa nacional contra a ameaça comunista vislumbrada pela ditadura Vargas. Nesse contexto, a Política Nacional de Bem-Estar do Menor (PNBEM) teve suas diretrizes fixadas pelo governo Castelo Branco - lei n. 4.513, de 1/12/64, cuja tônica era a valorização da vida familiar e da "integração do menor na comunidade". O regime militar acreditava que os grupos de "menores" circulando livremente pelas vias públicas colocavam em risco a segurança coletiva, pois não apenas participavam ostensivamente de crimes contra o patrimônio, como também seriam autores de homicídios e por isso deveriam ser controlados e contidos. Em consequência, o Estado passou a adotar um conjunto de medidas que têm por alvo a "conduta antissocial" do "menor", entre elas o recolhimento de jovens pela polícia e seu posterior encaminhamento a FUNABEM (CFESS, 2003).

O segundo Código de Menores surgiu no período em que se iniciava no Brasil a discussão da abertura política, e se constitui numa tentativa de intermediar o modelo em vigor e as críticas ao modelo repressivo das políticas sociais para a infância. O texto de 1979 abria mão da classificação da infância em "abandonada" ou "delinquente", mas disfarçava a categoria "abandonado" na análise das condições sociais e econômicas da família, defendendo o abandono material como argumento jurídico válido para a intervenção estatal na família e para a cassação - temporária ou definitiva - do pátrio poder. Com base em tais paradigmas, o Código de 1979 ampliou em muito o poder dos magistrados, praticamente centralizando nos juízes o poder de acusar.

As críticas ao Código de 1979 se evidenciaram desde a sua promulgação e, na esteira do processo de redemocratização da sociedade brasileira, ocorrido na década de 1980, movimentos sociais se manifestaram a favor da publicação de um novo texto para a infância e juventude brasileiras, articulando-se através do Fórum dos Direitos da Criança e do Adolescente, cujo principal alvo era a Reforma Constitucional. Esse movimento conquistou importante vitória política ao inscrever no texto constitucional de 1988, pela primeira vez na história brasileira, a concepção da criança e do adolescente como cidadãos e sujeitos de direitos sociais, políticos e jurídicos.

O ECA é o texto legal que consolida esses direitos constitucionais. A Doutrina da Proteção Integral é a principal inspiração do ECA e se insere no contexto em que o Brasil assume o compromisso político, diante da comunidade internacional, de implementar e 
defender os termos propostos em marcos legislativos internacionais, como a Declaração dos Direitos da Criança (de 1959) e a Convenção dos Direitos da Criança (de 1989).

A mudança da Doutrina da Situação Irregular para a de Proteção Integral, num contexto político de abertura democrática e de garantia de direitos, promoveu o ideário socioeducativo quando aplicadas as medidas judiciais. Donde vislumbramos em certa medida, a exemplo do contexto europeu de início do século XX retratado acima por Donzelot (1980), o triunfo da tendência familiarista - também de caráter jurídico e nacionalista - sobre a tendência medicalizante que predominou nos códigos anteriores, especialmente no de 1927.

Em poucas linhas, sabemos que o ECA prevê medidas socioeducativas a serem infligidas aos adolescentes autores de ato infracional, possuindo caráter punitivo, porém, também educacional. Contudo, como observa Teixeira, "os agentes executores das medidas de meio aberto esquecem ou falseiam o aspecto punitivo e, por outro lado, as condições precárias de cumprimento da medida de privação de liberdade (...) demonstram a irrelevância atribuída ao aspecto educacional" (Teixeira, 2014, p.167). Ademais, a medida socioeducativa "tem um caráter pedagógico relacionado à responsabilização do adolescente pelas suas ações” (Teixeira, 2014, p. 168).

O hiato existente entre a previsão legal da educação, de um lado e de outro lado, as práticas punitivas e degradantes das instituições demonstram como o direito serve de vetor e invólucro das estratégias de normalização e disciplina que, por sua vez, são incorporadas à cena jurídica, penal e punitiva. Quando se quer objetar contra as disciplinas, evoca-se o Direito formal, diria Foucault (1991), embora ambos sejam duas partes constitutivas dos mecanismos gerais do poder. Expliquemo-nos: o poder se organizou em termos de disciplina nos séculos XVII-XVIII, não sendo possível descrevê-lo como soberania, embora a teoria a respeito dessa última não tenha caído por terra. Ao contrário, a teoria da soberania persistiu como ideologia e como princípio organizador dos códigos jurídicos. Isso porque um poder complementa o outro, especialmente porque a soberania permitiu sobrepor à disciplina um sistema de Direito que oculta sua dominação. Em outras palavras, a disciplina funciona como mecanismo de dominação ao mesmo tempo em que se camufla enquanto exercício do poder. O Direito permite sua camuflagem e, portanto, sua eficácia. Portanto, o poder se exerce na fronteira entre o discurso jurídico da soberania e o mecanismo da disciplina (Foucault, 1987).

A camuflagem das estratégias de normalização e de disciplina, no interior da tendência familiarista a que nos referíamos acima, torna-se completa com a substituição definitiva do psiquiatra pela presença das equipes interprofissionais que, na qualidade de serviços auxiliares, tem como atribuição, no Art. 151 do ECA, "fornecer subsídios por escrito, mediante laudos, ou verbalmente, na audiência, e bem assim desenvolver trabalhos de aconselhamento, orientação, encaminhamento, prevenção e outros, tudo sob a imediata subordinação à autoridade judiciária, assegurada a livre manifestação do ponto de vista técnico".

Por fim, a responsabilização idealizada na aplicação de medidas judiciais não se limita ao adolescente, mas à sua família, tal qual podemos observar no art. 100 que assinala a preferência por aquelas que visem ao fortalecimento dos vínculos familiares e comunitários. O enquadre legal recomenda que se privilegie o convívio familiar, cuja inclinação não era evidente no antigo Código. 
Encontramos, em suma, as linhas de força que compõem o cenário de entrada da figura do psicólogo no campo jurídico. O resgate do poder simbólico do juiz, a normalização e, ao mesmo tempo, a flexibilização das relações de aliança, a centralidade da criança, a produção de virtualidades para além do campo criminológico e a generalização da perícia constituem, entre outros fatores, a base da inscrição da perícia psicológica.

\section{Considerações finais}

A investigação teórica sobre as condições de existência da forte demanda no campo jurídico por laudos e pareceres psicológicos, com base na perícia e na avaliação, possui como chave explicativa as práticas de poder que o direito coloca em marcha. Com a mudança da Doutrina da Situação Irregular, que marcaram os já revogados Códigos de Menores no Brasil, para a Doutrina da Proteção Integral, presente no ECA, modificaram muito pouco o efeito persuasivo que laudos e pareceres exercem sobre os operadores de direito. Mesmo sendo portadores de uma forte herança da tendência medicalizante, laudos e pareceres são ainda exigidos a despeito da tendência familiarista, jurídico e nacionalista que pesa parcialmente sobre o ECA. A razão para tanto se deve ao fato de o direito servir de vetor e, ao mesmo tempo, camuflagem para as estratégias de normalização e disciplina, havendo uma colonização recíproca entre tais domínios. Em sendo assim, a demanda insensata de laudos e pareceres servem a diversas linhas de força, entre as quais, o resgate do poder simbólico do juiz que até então poderia ser afrontada pela corrente medicalizante.

Para concluir, é importante destacar que, como todo e qualquer texto legal, o ECA condensa uma diversidade de demandas em sua origem, das quais uma dela é a de desjudicialização, por meio da qual, por exemplo, foram criados conselhos com participação da sociedade civil. Assim, no cerne da própria lei encontra-se a perspectiva para além da tendência familiarista ou qualquer outra mencionada acima, cabendo ao psicólogo tomá-la como pressuposto ético para o enfrentamento das práticas de poder que procuram subjugar a vida humana, mesmo que ele esteja investido da tarefa de confeccionar laudos e pareceres.

\section{Referências}

Brandão, E. P. \& Gonçalves, H. S. (orgs.) (2011). Psicologia Jurídica no Brasil. Rio de Janeiro: Nau.

Brandão, E. P. (2012). Sexualidade e Aliança na Contemporaneidade - Nem Édipo, Nem Barbárie: Uma Contribuição Genealógica ao Debate Psicanalítico. Curitiba: Juruá.

Brito, L. M. T. (2008). Família e separações: Perspectivas da Psicologia Jurídica. Rio de Janeiro: Editora da Universidade do Estado do Rio de Janeiro.

CEFSS (org), (2003). O Estudo Social em perícias, laudos e pareceres técnicos. Contribuição ao debate no Judiciário, Penitenciário e na Previdência Social. São Paulo: Cortez. 
Donzelot, J. (1980) A Polícia das Famílias. Rio de Janeiro: Graal.

Fávero, E. Melão, M. \& Tolosa, J. (2005) O Serviço Social e a Psicologia no Judiciário: construindo saberes, conquistando direitos. São Paulo: Cortez.

Foucault, M. (1987) Vigiar e Punir; nascimento da prisão. Petrópolis: Vozes. (1994). História da Sexualidade: o uso dos prazeres. Rio de Janeiro: Graal. . (1996) A Verdade e as Formas Jurídicas. Rio de Janeiro: Nau. . (2011) Os Anormais. São Paulo: Martins Fontes.

Garcia-Roza, L. A. (2000) Freud e o Inconsciente. Rio de Janeiro: Jorge Zahar.

Groeninga, G. C. \& Pereira, R. C. (Orgs.), (2003). Direito de família e psicanálise: Rumo a uma nova epistemologia. Rio de Janeiro: Imago.

Lago, V. M. Amato, P. Teixeira, P. A. Rovinski S. L. R. \& Bandeira, D. R. (2009) Um breve histórico da psicologia jurídica no Brasil e seus campos de atuação. Estudos de psicologia (Campinas) vol.26 no.4 Campinas Nov./Dec. 2009. Recuperado em 14 janeiro, 2016, de http://www.scielo.br/scielo.php?pid=S0103166X2009000400009\&script=sci_arttext

Piedade, E. (2011) (Des) construindo a 'menoridade': a psicologia e a produção da categoria "menor". In Brandão, E. P. \& Gonçalves, H. S. (orgs.), Psicologia Jurídica no Brasil. Rio de Janeiro: Nau.

Rabinow, P. (1999) Antropologia da Razão. Rio de Janeiro: Relume-Dumará.

Reis, E. F. (2008). Varas de Família: Um encontro entre psicologia e direito. Curitiba: Juruá.

Rizzini, I. \& Rizzini, I. (2004) A Institucionalização de Crianças no Brasil; percurso histórico e desafios do presente. Rio de Janeiro: Ed. PUC-Rio; São Paulo: Loyola.

Teixeira, M. L. (2014). Medida Socioeducativa. In Lazzzarotto, Gislei et al. Medida Socioeducativa entre A\& Z. Porto Alegre: UFRGS; Evangraf.

Zamora, M.H., Pereira, I. (2013). Adolescente em conflito com a lei e suas famílias. In Julião, E. \& Vergílio, S. (Org.). Juventudes, políticas públicas e medidas socioeducativas. RJ: DEGASE.

Recebido / Received: 28/10/2015

Aprovado / Approved: 15/01/2016 